\title{
Adipösen hilft Empathie statt Moralpredigten
}

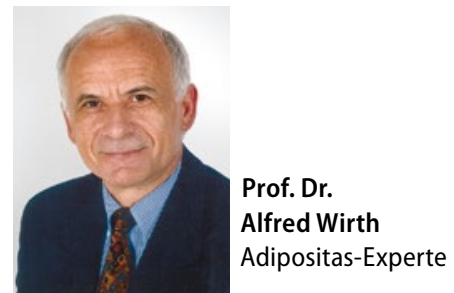

\begin{abstract}
Dass sie sich beim Essen mal beherrschen müssten, haben übergewichtige Patienten schon tausend Mal gehört - auch von Ärzten. Dabei wäre es unsere Aufgabe, sie klar über die Krankheit Adipositas zu informieren, ihnen realistische Ziele aufzuzeigen und sie mit Empathie zu unterstützen.
\end{abstract}

_ Jetzt im Frühjahr sind die Zeitschriften und Blogs wieder mit Turbo-Diätplänen gefüllt. Doch Wissenschaftler sind sich einig: Lebensstiländerungen helfen nur einzelnen wenigen Patienten. Das Zauberwort heißt nicht Verhaltensprävention - sondern Verhältnisprävention. Ändern müssen sich die allgemeinen Lebensumstände, die Lebensmittelund Sportangebote usw.

Dies ist v. a. ein Appell an die Politiker. Ähnlich wie in Finnland sollten auch bei uns Kitas, Schulen, Betriebe, Gemeinden usw. Voraussetzungen für eine gesunde Lebensweise schaffen. Wir sollten adipogene Lebensmittel besteuern und mit den Einnahmen Obst und Gemüse finanziell unterstützen.

Wir Ärzte hingegen sind weniger bei der Prävention, sondern vielmehr bei der Therapie gefordert. Dabei gilt: Wir können nicht allen helfen. Unterstützen sollten wir vorwiegend hoffnungsvolle Patienten mit Aussicht auf Therapieerfolg; das ist nicht unethisch. Adipöse brauchen unsere Hilfe, aber auch die von Ernährungsfachkräften, Sporttherapeuten und Psychologen.

Welche Themen gibt es für das Patientengespräch? Zunächst einmal: Adipositas ist zur Hälfte genetisch be- dingt. Hat man durch die Anamnese den Eindruck, der Patient isst und bewegt sich wie andere Personen, entlastet ihn diese Information psychisch enorm - und schafft Vertrauen. Das hat er bisher wahrscheinlich noch nie gehört, sondern eher, dass er sich „zusammenreißen“ oder das „Frustessen“ aufgeben solle. Nur ein empathischer Arzt ist ein guter Adipositastherapeut.

\section{Eine eigenständige Krankheit}

Patienten fragen oft nach Tipps für schnelle Erfolge. Man muss ihnen vermitteln, dass Adipositas kein Symptom ist, sondern eine chronische Krankheit, die langfristig behandelt werden muss. Man sollte ihnen nicht mit 20 adipositasassoziierte Krankheiten Angst einjagen. Wer jedoch eine Gonarthrose bei einem Gewicht von $120 \mathrm{~kg}$ aufweist, den kann man auf den Zusammenhang hinweisen und eine Linderung durch Gewichtsreduktion versprechen. Ähnlich groß sind Leidensdruck und Therapiepotenzial z. B. bei Frauen mit Harninkontinenz.

Für den Erfolg der Gewichtsabnahme sind die Persönlichkeit des Patienten, seine Vorerfahrungen und

Mit einem ewigen schlechten Gewissen ist ihr nicht geholfen. psychosozialen Umstände sowie das Therapiekonzept wichtig. Hat der $\mathrm{Pa}$ tient sich realistische Lebensstiländerungen ausgedacht, sollte man ihn darin bestärken, statt ihm eigene Ideen aufzuzwingen. Studien belegen, dass allein das Energiedefizit für die Gewichtsabnahme relevant ist. Alle Maßnahmen sollten sich daran orientieren.

Fragen Sie Adipöse bei jedem Besuch nach ihrem Gewicht, nach Ernährung und Bewegung. Hat der Patient Gewicht abgenommen, und wenn es nur wenig ist, loben Sie ihn! Sehr wahrscheinlich sind Sie der einzige, der ihm diese Aufmerksamkeit gibt. Viele Adipöse sind sozial isoliert und ohne jede Stütze.

\section{Reha-Maßnahmen sind möglich}

Als Hausarzt muss man Adipöse nicht selbst behandeln. Die Deutsche Adipositas Gesellschaft führt in ihrer S3-Leitlinie (www.adipositas-gesellschaft.de/ index.php?id=9) ambulante Programme auf, die ganz oder teilweise von den Krankenkassen bezahlt werden und die Patienten über längere Zeit in eine Gruppe einbinden.

Auch ambulante oder stationäre Reha-Maßnahmen kommen infrage, wenn die Berufsfähigkeit eines Patienten bedroht oder gemindert ist. Verabschieden Sie ihn dann aber bitte nicht mit den Worten: „Nun lassen Sie sich aber mal richtig schön verwöhnen!“

- Der Autor ist Beirat der Deutschen Adipositas Gesellschaft 